\title{
Making Teacher-Student Interaction Humorous Through Xiangsheng Techniques in the Chinese EFL Classroom
}

\author{
Hongji Jiang (Corresponding author) \\ School of educational studies, Universiti Sains Malaysia \\ Lai Mei Leong \\ School of educational studies, Universiti Sains Malaysia
}

Received: March 4, 2021 Accepted: March 17, $2021 \quad$ Published: March 21, 2021

doi:10.5296/ijele.v9i1.18435 URL: https://doi.org/10.5296/ijele.v9i1.18435

\begin{abstract}
This paper aims to propose the use of Xiangsheng techniques in the Chinese EFL classroom. Many previous studies have discussed the perceptions and benefits of the use of humor in the language classroom, but there are rarely any discussions on how to initiate humor. This article summarizes 10 Xiangsheng techniques, which meant to engage teachers and students in interactions which are both interesting and humorous. It is hoped that these Xiangsheng techniques will be able to provide insights into the use of humor for those teachers who wish to use it in their language classrooms.
\end{abstract}

Keywords: Humor, Xiangsheng, EFL classroom, Chinese culture 


\section{Introduction}

The use of humor has direct and indirect benefits in the EFL classroom, such as increased comprehension, cognitive retention, interest, and task performance, besides enhanced motivation, satisfaction, creativity, and divergent thinking (N. D. Bell \& Pomerantz, 2016; Berk, 2000, 2001; Decker, Yao, \& Calo, 2011; Martin, 1998; Wilkins \& Eisenbraun, 2009). Humor in Chinese EFL classrooms is valuable because the atmosphere in the Chinese classroom is generally quite tense due to the competition between students or peer pressure and the pressure of speaking or presenting on formal and public occasions. Moreover, it is likely that teachers have used humor for as long as there have been educational institutions (Melissa B. Wanzer, Frymier, \& Irwin, 2010). It is noted that the classroom is not a comedy club and using humor is not mandatory although we promote using humor in the foreign language classroom for its numerous benefits.

Previous research on humor tends to investigate the benefits and the types of humor, and the perceptions of students and teachers of using humor in the EFL classroom (Askildson, 2005; T. R. Bell, 2005; Berk, 2000; Chabeli, 2008; Huss \& Eastep, 2016; Pomerantz \& Bell, 2011). Moreover, there is little awareness of how to use humor, especially in spontaneous conversation. Therefore, this paper focuses on the techniques in spontaneous conversational humor, such as Xiangsheng techniques in teacher-student interaction (Martin, 2007). Chinese Xiangsheng is a kind of crosstalk that is always pre-scripted, following a set format but appears unrehearsed (Lawson, Sims, \& Lawson, 2020). The use of Xiangsheng techniques in the language classroom is meant to engage students to make the interaction vivid and creative. It is hoped that the ten Xiangsheng techniques in this article would be able to offer the methods that can be used in the second language classroom, especially for those teachers who wish to incorporate humor into their lessons.

\section{Literature Review}

Humor is an extensive term that refers to anything that people do or say that is comprehended as funny, comical, or amusing and tends to make others laugh (Graesser \& Long, 1988; Martin, 2007). The Cambridge Dictionary defines humor as amusement, the ability to be amused by something seen, heard, or thought about, sometimes causing you to smile or laugh, or the quality in something that causes such amusement. The Oxford English Dictionary defines humor as the quality in something that makes it funny or the ability to laugh at things that are funny. Martin (2007) regards that humor is also a mental process that goes into both perceiving and creating such an amusing stimulus, and also the affective response involved in its enjoyment. Although the definitions of humor vary, there is extensive agreement among scholars that humor involves the communication of multiple, incongruous meanings that are amusing in some manner (Martin, 2007). Different scholars have different classifications, Martin (2007) categorizes three types of humor: (i) jokes, (ii) spontaneous conversational humor, and (iii) accidental or unintentional humor. The spontaneous conversational humor is the focus in this paper. 
In China, humor was first recorded and documented about 2,000 years ago, and the Chinese word huaji (滑稽) is thought of as an optional word for humor, meaning wit, irony, and sarcasm (X. Yue, 2010; X. Yue, Jiang, Lu, \& Hiranandani, 2016). It was Lin Yutang who first coined the Chinese term (幽默) in 1924 and introduced and promoted the idea of humor in Chinese culture (Qian, 2007). Yue (2010) elaborates on the different historical perceptions and influences on humor from different philosophical schools such as Confucianism, Taoism, and Buddhism. Humor is both universal and specific. Although humor has a biological fundament implanted in human genes, it is also found that cultural norms and individual knowledge play an important role in determining how it is used in communications, and what topics are considered appropriate for it (Martin, 2007). Moreover, even people who share the same ethnicity, culture, or language might not share the same sense of humor. Actually, even jokes from the past often fail to amuse the modern hearer (N. d Bell \& Pomerantz, 2016). Since the planned jokes conform so strongly to targeted generic conventions, it is possible to engage in meta-humor.

In principal, collectivism, socialization for achievement, and high acceptance of power and authority are strongly characterized in Chinese culture (Rao, 2006). Learning and teaching have been seen as formal and serious acts in Chinese conventional culture, so humor was ignored and lag far behind other teachers' abilities (Frymier \& Houser, 2000; Keeley, Ismail, \& Buskist, 2016; Richmond, Berglund, Epelbaum, \& Klein, 2015). Besides, Chinese humor varies considerably when compared to the humor in western culture. Previous research has attested that the Chinese do not view humor positively like their Western counterparts- They tend to value humor but consider themselves to lack humor (X. D. Yue, 2011), so most of them has ambivalent attitudes toward humor. Therefore, this perception makes the Chinese less likely to use humor as a coping strategy in comparison with Westerners. However, it is necessary to notice that culture is not a stable construct. Globalization has brought about big changes in human psychology and culture. Caution should be taken when concluding cultural differences in humor from the common perspective. So the Chinese attitudes to humor may be changed in this rapidly changing age (Jiang, Li, \& Hou, 2019).

While Western comedy is increasingly becoming more popular, the stereotype of China as a country devoid of humor has taken root gradually. Some claim China lacks humor and comedy. For example, Jimmy O. Yang, a Hong Kong-born American comedian, and Russell Peters, a Canadian comedian of Indian roots, have both joked that China is a place devoid of humor (Piwowarczyk, 2019). However, their statements are not true. There is no doubt that China has a rich culture of humor historically and currently - even despite Confucianism's ambivalent or even unfriendly stance. People who are interested in Chinese culture are familiar with Chinese crosstalk, also known as Xiangsheng. It is a traditional performing art in Chinese comedy, and one of the most popular elements of Chinese culture. It is typically performed as a dialogue between two performers. The 10 frequently-used Xiangsheng techniques summarized in this study are based on different books and articles (Chen, 2006; Guo, 2018; Hou, Xue, Wang, \& Li, 1982; P. Zhang \& Chen, 2018) and Dyment's techniques of creating humor (Dyment, 2020). All sketches are from the Xiangsheng performances of Guo Degang and Yu Qian who are the two most famous Xiangsheng artists in China. 


\section{Statement of Problem}

The use of humor in the language classroom in China has been underestimated for many reasons. In Chinese traditional English classes, teachers often give all students undifferentiated teaching according to the national prescribed teaching syllabus and teaching tasks. Most Chinese teachers are in favor of traditional pedagogical approaches like the grammar-translation method and audio-lingual method that allow teachers maximum control and opportunity to transmit knowledge (Barnard, Richards, \& Rodgers, 2002; Hu, 2002; Wen \& Clément, 2003). Although the CLT and TBLT approaches were introduced and advocated in China many decades ago, the emphasis is on traditional Chinese education which maintains a hierarchical but harmonious relation between teachers and students (Liu, 2015; D. Zhang, Li, \& Wang, 2013). However, the drawbacks of such a teaching approach will produce problems like a single teaching model and a dull classroom atmosphere. The traditional teaching model of "Teacher-centeredness" is far from meeting the needs of Chinese students in the new era.

The communicative approach has been introduced into Chinese EFL education recently to address the weakness of learners' communicative ability. Traditionally, due to the influence of Chinese philosophy, culture, and basic concepts of education, English teaching in China is dominated by a teacher-centered, book-centered, grammar-translation method, and an emphasis on rote memory ( $\mathrm{Hu}, 2002$; Rao, 1996). Based on the Chinese centralized curriculum, almost all English textbooks are designed to teach reading and writing with little emphasis on speaking and listening, let alone activities such as games or role-playing (Rao, 1996). Besides, English is mainly taught by Chinese teachers, and the majority of them have never been outside of China or talked to a foreigner (Cortazzi \& Jin, 1996b). A lot of them worried about not being able to respond to spontaneous questions related to the target language, sociolinguistics, or culture from interactions in the classroom. So it is difficult for the Chinese teachers to use humor through a non-native language.

However, with the promotion of the CLT approach, the Chinese curriculum and the attitude of the Chinese students are changing (Cortazzi \& Jin, 1996a, 1996b). In recent years, oral English tests are being prepared to be added to the College Entrance Exam and College English Test. For this form of examination, it is assumed that teachers will pay more attention to the communication part, which may affect the use of humor. However, there are rarely empirical studies on the use of humor in EFL classes in the Chinese context while this research area has been explored in other contexts. The reviews of the studies mainly discuss the benefits of humor on language learning (Bell \& Pomerantz, 2014; Deneire, 1995; Reddington, 2015), but how to use humor in classroom is under-researched.

\section{Method: Xiangsheng and Its Techniques}

Chinese Xiangsheng is a kind of crosstalk that is always pre-scripted, following a set format but appears unrehearsed. Comedic results will be reached when the baofu (package) is unpacked (Lawson et al., 2020). Xiangsheng 相声, literally meaning "face and voice", 


\section{Macrothink}

indicating that the art form primarily emphasizes facial expression and vocal skills (Moser, 2018). Standard Xiangsheng performance has two actors standing up on a stage:, one is penggende, "joke supporter" while the other is dougende, "joke cracker". For instance, Guo Degang (Guo) and Yu Qian (Yu), are two of China's most popular crosstalk actors. Guo is the protagonist as a "joke cracker" while Yu is a "joke supporter".

Although Xiangsheng is a Chinese traditional performance, it has regained the popularity of the audience especially the young generation nowadays. The emergence of the Chinese internet in the 2000s opened new spaces for humor and satire, and the punchline can spread overnight. The popularity of Guo Degang's Xiangsheng performance provides an example of revitalization in the comedy in this information era. However, the Chinese Xiangsheng is not exactly the same as western crosstalk or talk show. In China, Xiangsheng, together with other popular folk art performing forms, has been under the surveillance of censorship (Cai, 2016). For instance, explicitly political content and risqué content are largely prohibited. All sketches quoted in this study, translated by the author, are from the Xiangsheng performances by Guo Degang and Yu Qian. The symbol @ recommended by Chafe (2007) represents laughter.Twosymbols@@indicate more intensity than@.

\subsection{Unexpected Endings}

(a)

Guo: Oh, thank you for sending flowers. Come on, don't waste your money. Especially the girl who gave flowers, I must criticize you.

Yu: Why?

Guo: Don't buy flowers. It's not easy to hold them. (@)

Yu: Hey, hey, hi.

Guo: I will be dead in 2 days. You don't know if I like it or not if you buy something else. Just leave the money. (@@)

Yu: Hey, what kind of person you are.

(b)

Guo: There is good news and bad news. Which one do you want to hear?

Yu: What is the bad news?

Guo: We are lost, and I don't know this place. I guess we will have to live off eating cow dung in the future.

Yu: What about the good news?

Guo: There is a lot of cowdung! (@@) 


\section{Ml Macrothink}

This Unexpected Endings technique is typically reflected in the incongruity theory in humor. If what occurs is unexpected and positive and we have the resources to respond effectively, we move into a state of joy-becoming happy, optimistic (Morrison, 2008). There are two unexpected endings in this sketch. The first one is that one should prise praise the people who had sent the flowers but Guo responded by saying that flowers are not easy to hold. Laughter is elicited when conforming to a Chinese phrase "Beneficial actions often go unappreciated." The second one is that Guo said "just leave the money", which is classified under unexpected endings because giving money to others is not in line with Chinese social norms. In the EFL classroom, the teacher can use this technique to yield humor or funny comments. Using this technique may need the instructor to break the general rules and regulations that have been implemented in conversations.

\subsection{Misunderstanding}

Guo: In the early years, Yu loved to sing. After the performance, he turned around and rushed to the KTV. Yu shouted when he entered KTV: Give me two! No over eighteen! (@)

Yu: What? What do you mean no over eighteen?

Guo: Fruit dishes. What do you think? (@@)

Yu: Ah... I thought it was time to increase the price.

Misunderstanding is a deliberate mechanism to mislead the audience from situations they are familiar with using literary devices which are not normally used in that particular context: In "give me two", Guo deliberately omits naming the objects leading to ambiguity. Then in "no over eighteen", the audience could associate the phrase with young bargirls whose age is not beyond eighteen. In Chinese culture, asking a lady to accompany you to sing a the KTV is a veiled negative behavior. Laughter is evoked when Guo clarifies that he was asking for fruit dishes. EFL teachers can use this technique to misunderstand students' speech in order to achieve a humorous outcome. For instance, teacher asks students: How many times do you do laundry a week? Students respond: Uh, five times a week. Teacher: Ah, one time a week. Crazy.

\subsection{Homophonic}

Guo: There is "Dai (catch) $\mathrm{Zu}$ (ethnic)" in Yunnan.

Yu: Dai(ethnic) people?

Guo: They all tied themselves.

Yu: Well, there are no more people left in this clan, right? (@) What is Dai Zu? 
Guo: Dai (catch) Zu. (@)

Yu: Dai (ethnic) Zu.

Guo: Is Dai different from Dai? (@)

Yu: They are not the same words

In this sketch, Dai (catch) and Dai(ethnic) have the same pronunciation in Mandarin. Guo intentionally interprets Dai ethic as another "wrong" meaning to achieve the comedic effects. In the EFL classroom, teachers can use English homophones. For instance, if the heel breaks on your shoe, you might fall. However, your injuries will heal over time.

\subsection{Pun}

Guo: Wu Minxia and Guo Jingjing! Back somersault, three and a half Zhou (weeks), and more than a month.

Yu: What happened to them? They are hanging on the board? What are they doing in one month?(@@)

Guo: What do you say in professional terms?

Yu: Don't say it if you don't know the terms. It's just back somersaulted a few Zhou (circuits).

Guo: How many Zhou (weeks)? Four weeks equals one month. (@)

In this sketch, Zhou, a polysemous word, has two meanings here: week and circuit. Guo used a pun to make sure that a misunderstanding occurred. The pun, is a form of language play that exploits multiple meanings of a term, or of similar-sounding words. However, for teachers, using a pun may be difficult, and also hard to be understood by students. For instance, "A chicken farmer's favorite car is a coupe." This is a pun because the car, a coupé, is pronounced the same way as a chicken house, which is also called a coupe. This technique requires higher language proficiency and cultural knowledge from teachers and students.

\subsection{Exaggeration}

(a)

Guo: There are a lot of people sitting here today, tens of thousands of people upstairs and downstairs.

(b) 


\section{Mll Macrothink}

Guo: There was a robber who was very successful. He robbed 1.83 million in cash. At 5:40 pm, when the police found him, he was still in traffic on the Third Ring Road of Beijing.

Kids love to exaggerate and it is an excellent way to engage with the audience as it uses humour which is relaxing. Using exaggerated tone or words may make students remember more and the class no longer boring. As an EFL teacher, using this technique (exaggeration) can make our class vivid and funny, especially in a class of younger students. However, using exaggeration in language classes is not necessarily only suitable for children but also teenager lerners, especially on describing something or learning adjectives.

\subsection{Self-Deprecating}

Guo: I want to open a hotel, but there is only one Valentine's Day every year.

Yu: It will be closed for the rest of the year, right?

Guo: Being a painter, I have color blindness. Being a doctor, I have blood phobia. Being a basketball player, their knees keep hitting the back of my head. (@ @ )

Guo was of short stature and often made fun of himself or allowed his colleagues to ridicule him during the Xiangcheng performance. However, teachers should be careful when using the self-deprecating technique. According to Frymier et al. (2008) and Wanzer et al. (2006), disparaging remarks and sarcasm are not appropriate humor. It may not be funny and could hurt the teacher's image in the students' eyes (Morrison, 2008; Pham Nguyen, 2014).

\subsection{Mock}

Guo: If you like me, please raise your left hand. If you like Yu, please stretch out your middle finger.

Like the self-deprecating technique, the mock technique should be used very carefully. Mocking is usually done with good friends who understand each other. However, mocking will lead to sarcastic humor which is regarded as inappropriate humor (Frymier, Wanzer, \& Wojtaszczyk, 2008; Melissa Bekelja Wanzer, Frymier, Wojtaszczyk, \& Smith, 2006a). Thus, it is best not to use mocking as a technique unless you are on familiar terms with the person.

\subsection{Imitations}

Guo: You don't understand science. The computer is high-tech. I have used a computer long ago.

Yu: Really?

Guo: When the computer came up, many people didn't know it. I was already Da (beating) 


\section{Macrothink}

the computer at home (Guo is doing beating moves).( @ @ )

Yu: You are smashing it, not playing a computer.

Guo: It is Da (playing) computer (Guo is doing beating moves). ( @ )

In this sketch, Guo brags that he knew science and how to use a computer, but from his imitation moves, the audience knows that he did not know how to use a computer at all. $D a$ (打), a polysemous word, has two meanings here: beat and play. Imitation is an important method in cross-talk. This kind of imitation has to be brilliant, and it has to be inadvertently slanted to create unexpected effects, rather than relying on grandstanding, or ugly behavior to win cheap laughter (X. D. Yue, 2011). In the EFL classroom, teachers can imitate a celebrity to demonstrate the accent of a certain place. For instance, when our audience is children, we use more movements or gestures. On the other hand, we may use more voice inflections than actions when students are older. Regardless of whether it is action imitation or sound imitation, teachers need to have a lot of training in order to do it.

\subsection{Flattering and Bragging}

Guo: OK, I write. I will be a great writer shortly. I swear, I will start studying tonight, and I won't do anything from this evening, just writing.

Yu: Oh, just practice calligraphy?

Guo: Hey, classical literature,

Yu: Can you?

Guo: No problem! I write "Outlaws of the Marsh" first.

Yu: You don't need to write "Outlaws of the Marsh", someone wrote it long ago.

Guo: I wrote him a little more complicated. ( @ )

Yu: Isn't that also "Outlaws of the Marsh"?

Guo: I blended "Three Kingdoms" and "Outlaws of the Marsh" together. ( @ )

Yu: Huh? Can that still be good to read?

Guo: Why can't you read? I wrote "Outlaws of the Marsh", a "Shuipo Liangshan", then a "The Story of Shuipo Liangshan", and "Liangshan Heros", and

Yu: What's the meaning of so many names for one book?

Guo: It's not the same. I will write "Xi Men Qing and His Women". ( @ @ ) This my favorite, and I write this first!

Outlaws of the Marsh is a part of Chinese classical literature. Guo brags that he will change the title of the book, plagiarize from other books, and finally merge it into his book. This bragging has ironic effects because it scorns the popular practice of persistent plagiarism. 
Flattering and bragging are often used in cross-talk to evoke ridiculte. However, teachers should exercise caution when using it in order to avoid the adverse effects such as contempt and humiliation.

\subsection{Omission}

Guo: When I was traveling in Yunnan and walking on the street, two women came to me: "Brother, let's see the dance!"

"What dance? "

"Ethnic style of dance."

"Oh, Beijing has it. "

"Have you seen dancers who don't wear clothes?"

"Without clothes?"

Yu: Ah?

Guo: Without clothes, how can I know what ethnicity is? No, thanks. ( @ @ )

In Guo's last sentence, he deliberately omits ethnic in "without clothes". Laughter appears after the audience hears an unexpected ending. In teacher-student communication, teachers can deliberately remove the words to achieve misunderstanding or unexpected endings for comedic effects.

\section{Discussion and Limitations}

The Xiangsheng techniques will help teachers to initiate humor in the EFL classroom. The obvious part of the humor in foreign language education concerns its indirect benefits. Researchers have found that humor can: lower students' affective filters, increase teacher immediacy and decrease the psychological distance between teachers and students, produce a safer, more open classroom environment (Askildson, 2005; Morrison, 2008; Pomerantz \& Bell, 2011; Melissa B. Wanzer et al., 2010). Berk (2000, 2001) reviewed the psychological effects on the reduction of anxiety, tension, and stress. Humor can reduce anxiety, tension, stress, depression, and loneliness. Moreover, humor can improve self-esteem, restore hope and energy, and provide a sense of empowerment and control (Berk, 2000, 2001). This tension-releasing function of humor has been mentioned by many researchers over the years (N. D. Bell, 2009; Deiter, 2000; Petraki \& Pham Nguyen, 2016; Torok, McMorris, \& Lin, 2004), and some have even proposed that tension relief is a determining feature of humor (Savage, Lujan, Thipparthi, \& DiCarlo, 2017). Many researchers have proposed that positive emotions play an important role in interpersonal relationships. These authors have remarked that humans are social animals that demand close relationships in order to survive (Martin, 2007). Attardo (2017) considered that as learning is an increasingly effective engagement in 
social action, the role that humor seems to play in facilitating the development of voices, registers, and styles becomes very important.

It is noted that the difficulty of transliteration from the Xiangsheng sketch existed, and some of the meaning is lost upon the non-Chinese reader consequently. The punchline is explained as follow, it seems not funny as explained. Because based on the incongruity theory, the punchline must create a different mental representation that conflicts with the one set up by the joke. Of the ten Xiangsheng techniques, there are three which may be difficult to implement in the EFL classroom: self-deprecating, mockery, flattering, and bragging. Teachers should use these carefully or not at all because they can easily lead to self-disparaging humor and sarcastic humor, which may not be that funny and could hurt the teacher's image in students' eyes (Morrison, 2008; Pham Nguyen, 2014). According to Frymier et al. (2008) and Wanzer et al. (2006), disparaging humor and sarcastic humor are not appropriate humor. Wanzer, Frymier and Irwin (2010) argued that not all forms of instructor-generated humor seem to be appropriate for the classroom, and even if it is appropriate it does not necessarily mean that it will increases student learning (Melissa B. Wanzer et al., 2010). Wanzer et al. (2010) proposed that humor related to instructional content would correlate positively with student learning, while inappropriate forms would not. The inappropriate humor that instructors joke about is probably going to cause students to feel awkward or uncomfortable, such as topics regarding religion, politics, sex, and ethnic issues (Frymier et al., 2008; Melissa Bekelja Wanzer, Frymier, Wojtaszczyk, \& Smith, 2006b). Thus, using humor in the classroom is not as easy as it seems. Instead, instructors should avoid inappropriate humor and use instructional content-related humor as much as possible.

Although being humorous is not a necessary competency for for language teachers, Chinese students prefer humour and fun, valuing these qualities in their teachers (Wu \& Huang, 2003). Using humor has a lot of direct and indirect benefits in the classroom, such as building a good rapport, increasing effective teaching, and enhancing student participation (Adamson, O'Kane, \& Shevlin, 2005; Estepp \& Roberts, 2015; Frisby \& Martin, 2010; Richmond et al., 2015). Moreover, the understanding of the humor instance needs requires shared awareness between the speakers and listeners of the implied meaning and is associated with socio-cultural values (Wang, 2014). So, Chinese EFL teachers may have difficulties with using some types of humor in the classroom. But Xiangsheng techniques would help them in spontaneous conversation. This paper has outlined the use of the Xiangsheng techniques to induce spontaneous conversational humor. It is beneficial for language teachers to know how to make use of these techniques in teaching a foreign language. However, It may be worthwhile to note that making teacher-student interaction humorous is a continuous process that can be sustained by various personal or situational motives.

\section{Acknowledgments}

We would like to thank the editors and the reviewer for devoting their time and expertise to this article. 


\section{References}

Adamson, G., O'Kane, D., \& Shevlin, M. (2005). Students' ratings of teaching effectiveness: A laughing matter? Psychological Reports, 96(1), 225-226. https://doi.org/10.2466/pr0.96.1.225-226

Askildson, L. (2005). Effects of Humor in the Language Classroom: Humor as a Pedagogical Tool in Theory and Practice. Working Papers in SLAT, 12, 45-61.

Barnard, R., Richards, J. C., \& Rodgers, T. S. (2002). Approaches and Methods in Language Teaching. TESOL Quarterly, 36(4), 636. https://doi.org/10.2307/3588247

Bell, N. D. (2009). Learning about and through humor in the second language classroom. Language Teaching Research, 13(3), 241-258. https://doi.org/10.1177/1362168809104697

Bell, N. D., \& Pomerantz, A. (2016). Humor in the Classroom: a guide for language teachers and educational researchers. In Routledge. https://doi.org/10.1080/00098655.1964.11476050

Bell, N. d, \& Pomerantz, A. (2016). Humor in the classroom a guide for language teachers and educational researchers. In Routledge.

Bell, N., \& Pomerantz, A. (2014). Reconsidering language teaching through a focus on humor. EuroAmerican Journal of Applied Linguistics and Languages, 1(1), 31-47. Retrieved from http://www.e-journall.org/wp-content/uploads/Bell_Pomerantz_1.1.pdf

Bell, T. R. (2005). Behaviors and attitudes of effective foreign language teachers: Results of a questionnaire study. Foreign Language Annals, 38(2), 259-270. https://doi.org/10.1111/j.1944-9720.2005.tb02490.x

Berk, R. A. (2000). Does Humor in Course Tests Reduce Anxiety and Improve Performance? College Teaching, 48(4), 151-158. https://doi.org/10.1080/87567550009595834

Berk, R. A. (2001). The active ingredients in humor: Psychophysiological benefits and risks for older adults. Educational Gerontology, 27(3-4), 323-339. https://doi.org/10.1080/036012701750195021

Cai, S. (2016). A culture hero: Xiangsheng (crosstalk) performer Guo Degang. Asian Theatre Journal, 33(1), 82-103. https://doi.org/10.1353/atj.2016.0000

Chabeli, M. (2008). Humor: a pedagogical tool to promote learning. Curationis, 31(3), 51-59. https://doi.org/10.4102/curationis.v31i3.1039

Chen, J. (2006). Xiangsheng youmo yanyu zhi yuyong celve yanjiu [A study on the pragmatic strategies of verbal humor in Xiangsheng]. Journal of Yanbei Nornal University, 22(4). https://doi.org/10.1017/CBO9781107415324.004

Cortazzi, M., \& Jin, L. (1996a). Cultures of learning: Language classrooms in China. In Society and the Language Classroom (pp. 169-206). 
https://doi.org/http://dx.doi.org/10.1097/01.ju.0000169487.49018.73

Cortazzi, M., \& Jin, L. (1996b). English teaching and learning in China. Language Teaching, 29(2), 61-80. https://doi.org/10.1017/S0261444800008351

Decker, W., Yao, H., \& Calo, T. (2011). Humor, Gender, and Perceived Leader Effectiveness in China. SAM Advanced Management Journal, 76(1), 43.

Deiter, R. (2000). The use of humor as a teaching tool in the college classroom. NACTA Journal, 20-28. Retrieved from https://manchester.idm.oclc.org/login?url=https://search.proquest.com/docview/3051590 97?accountid=12253\%0Ahttp://man-fe.hosted.exlibrisgroup.com/openurl/44MAN/44M AN_services_page?genre $=$ dissertations $+\% 26+$ theses \&atitle $=\&$ author $=$ Lukehart $\% 2 \mathrm{C}+\mathrm{D}$ ennis + E. $\&$ volume $=\&$

Deneire, M. (1995). Humor and foreign language teaching. Humor, 8(3), 285-298. https://doi.org/10.1515/humr.1995.8.3.285

Dyment, B. (2020). The Science of Creating Humor: 20 techniques you can use immediately. $\begin{array}{llll}\text { Retrieved July 21, 2020, from } & \text { 21 }\end{array}$ https://drbillspeaks.com/the-science-of-creating-humor-20-techniques-you-can-use-imm ediately-to-make-your-presentations-introductions-and-stories-more-humorous/

Estepp, C. M., \& Roberts, T. G. (2015). Teacher immediacy and professor/student rapport as predictors of motivation and engagement. NACTA Journal, 59(2), 155-164.

Frisby, B. N., \& Martin, M. M. (2010). Instructor - Student and student - Student rapport in the classroom. Communication Education, 59(2), 146-164. https://doi.org/10.1080/03634520903564362

Frymier, A. B., \& Houser, M. L. (2000). The teacher-student relationship as an interpersonal relationship. Communication Education, 49(3), 207-219. https://doi.org/10.1080/03634520009379209

Frymier, A. B., Wanzer, M. B., \& Wojtaszczyk, A. M. (2008). Assessing students' perceptions of inappropriate and appropriate teacher humor. Communication Education, 57(2), 266288. https://doi.org/10.1080/03634520701687183

Graesser, A. C., \& Long, D. (1988). Wit and Humor in Discourse Processing. Discourse Processes, 11(1), 35-60. https://doi.org/10.1080/01638538809544690

Guo, D. (2018). Guo lun [Guo Theory]. In Hunan Literature and Art Publishing House.

Hou, B., Xue, B., Wang, J., \& Li, W. (1982). Xiangsheng suyuan [The origin of cross talk]. In People's Literature Publishing House.

Hu, G. (2002). Potential cultural resistance to pedagogical imports: The case of communicative language teaching in china. Language, Culture and Curriculum, 15(2), 93-105. https://doi.org/10.1080/07908310208666636 
Huss, J., \& Eastep, S. (2016). The Attitudes of University Faculty toward Humor as a Pedagogical Tool: Can We Take a Joke? Journal of Inquiry and Action in Education, $8(1), 39-65$.

Jiang, T., Li, H., \& Hou, Y. (2019). Cultural differences in humor perception, usage, and implications. Frontiers in Psychology, 10(JAN), 1-8. https://doi.org/10.3389/fpsyg.2019.00123

Keeley, J. W., Ismail, E., \& Buskist, W. (2016). Excellent Teachers' Perspectives on Excellent Teaching. Teaching of Psychology, 43(3), 175-179. https://doi.org/10.1177/0098628316649307

Lawson, F., Sims, J. D., \& Lawson, J. S. (2020). When Audiences Become Performers and Speech Becomes Music: New Tools to Analyze Speech, Song, and Participation in Chinese Crosstalk. Music \& Science, 3, 205920432093798. https://doi.org/10.1177/2059204320937986

Liu, S. (2015). Reflections on Communicative Language Teaching and Its Application in China . Theory and Practice in Language Studies, 5(5), 1047. https://doi.org/10.17507/tpls.0505.20

Martin, R. A. (1998). Approaches to the sense of humor: A historical review Humor and sense of humor. The Sense of Humor: Explorations of a Personality Characteristic, 15.

Martin, R. A. (2007). The Psychology of Humor. In The Psychology of Humor. https://doi.org/10.1016/B978-0-12-372564-6.X5017-5

Morrison, M. K. (2008). Using humor to maximize learning: The links between positive emotions and education. In $R \& L$ Education. Rowman \& Littlefield Education.

Moser, D. (2018). Keeping the Ci in Fengci: A Brief History of the Chinese Verbal Art of Xiangsheng. In Not Just a Laughing Matter (Vol. 5, pp. 77-95). https://doi.org/10.1007/978-981-10-4960-6

Petraki, E., \& Pham Nguyen, H. H. (2016). Do Asian EFL teachers use humor in the classroom? A case study of Vietnamese EFL university teachers. System, 61, 98-109. https://doi.org/10.1016/j.system.2016.08.002

Pham Nguyen, H. H. (2014). The use of humour in EFL teaching : A case study of Vietnamese university teachers ' and students 'perceptions and practices The use of humour in EFL teaching: A case study of Vietnamese university teachers 'and students '. University of Canberra, Australia.

Piwowarczyk, K. (2019). Chinese and Western Comedy - an Introduction into Cross-Cultural Humour Research between Taiwan, China and the West. Nowa Polityka Wschodnia, 20(1), 23-39. https://doi.org/10.15804/npw20192002

Pomerantz, A., \& Bell, N. D. (2011). Humor as Safe House in the Foreign Language Classroom. Modern Language Journal, 95(SUPPL. 1), 148-161. 
https://doi.org/10.1111/j.1540-4781.2011.01274.x

Qian, S. (2007). Translating "humor" into Chinese culture. Humor, 20(3), 277-295. https://doi.org/10.1515/HUMOR.2007.014

Rao, Z. (1996). Reconciling Communicative Approaches to the Teaching of English with Traditional Chinese Methods. Research in the Teaching of English, 30(4), 458-471.

Rao, Z. (2006). Understanding Chinese students' use of language learning strategies from cultural and educational perspectives. Journal of Multilingual and Multicultural Development, 27(6), 491-508. https://doi.org/10.2167/jmmd449.1

Reddington, E. (2015). Humor and Play in Language Classroom Interaction: A Review of the Literature. Working Papers in TESOL \& Applied Linguistics, 15(2), 22-38. Retrieved from

https://search.ebscohost.com/login.aspx?direct=true \&db=eric\&AN=EJ1176846\&lang=fr \&site $=$ ehost-live

Richmond, A. S., Berglund, M. B., Epelbaum, V. B., \& Klein, E. M. (2015). a + (b1) Professor-Student Rapport + (b2) Humor + (b3) Student Engagement = (Y) Student Ratings of Instructors. Teaching of Psychology, 42(2), 119-125. https://doi.org/10.1177/0098628315569924

Savage, B. M., Lujan, H. L., Thipparthi, R. R., \& DiCarlo, S. E. (2017). Humor, laughter, learning, and health! A brief review. Advances in Physiology Education, 41(3), 341-347. https://doi.org/10.1152/advan.00030.2017

Torok, S. E., McMorris, R. F., \& Lin, W. C. (2004). Is Humor an Appreciated Teaching Tool? Perceptions of Professors' Teaching Styles and Use of Humor. College Teaching, 52(1), 14-20. https://doi.org/10.3200/CTCH.52.1.14-20

Wang, Y. (2014). Humor in British academic lectures and Chinese students' perceptions of it. Journal of Pragmatics, 68, 80-93. https://doi.org/10.1016/j.pragma.2014.05.003

Wanzer, Melissa B., Frymier, A. B., \& Irwin, J. (2010). An explanation of the relationship between instructor humor and student learning: Instructional humor processing theory. Communication Education, 59(1), 1-18. https://doi.org/10.1080/03634520903367238

Wanzer, Melissa Bekelja, Frymier, A. B., Wojtaszczyk, A. M., \& Smith, T. (2006a). Appropriate and inappropriate uses of humor by teachers. Communication Education, 55(2), 178-196. https://doi.org/10.1080/03634520600566132

Wanzer, Melissa Bekelja, Frymier, A. B., Wojtaszczyk, A. M., \& Smith, T. (2006b). Appropriate and inappropriate uses of humor by teachers. Communication Education, 55(2), 178-196. https://doi.org/10.1080/03634520600566132

Wen, W. P., \& Clément, R. (2003). A chinese conceptualisation of willingness to communicate in esl. Language, Culture and Curriculum, 16(1), 18-38. https://doi.org/10.1080/07908310308666654 
Wilkins, J., \& Eisenbraun, A. J. (2009). Humor theories and the physiological benefits of laughter. Advances in Mind-Body Medicine, 24(2), 8-12.

Wu, G., \& Huang, X. (2003). Dangdai zhongxuesheng xiai de jiaoshi renge tezheng yanjiu [A study on the personality characteristics of teachers favored by Middle School Students]. Educational Research and Experiment, 4.

Yue, X. (2010). Exploration of Chinese humor: Historical review, empirical findings, and critical reflections. Humor, 23(3), 403-420. https://doi.org/10.1515/HUMR.2010.018

Yue, X. D. (2011). The Chinese ambivalence to humor: Views from undergraduates in Hong Kong and China. Humor, 24(4), 463-480. https://doi.org/10.1515/HUMR.2011.026

Yue, X., Jiang, F., Lu, S., \& Hiranandani, N. (2016). To be or not to be humorous? Cross cultural perspectives on humor. Frontiers in Psychology, 7(OCT), 1-10. https://doi.org/10.3389/fpsyg.2016.01495

Zhang, D., Li, Y., \& Wang, Y. (2013). How Culturally Appropriate Is the Communicative Approach with Reference to the Chinese Context? Creative Education, 04(10), 1-5. https://doi.org/10.4236/ce.2013.410a001

Zhang, P., \& Chen, Z. (2018). Shixie lilun shiyu xia Xiangsheng de youmo jifa ji yuanli chanshi [Humorous techniques and principle explanation of Chinese Cross Talk from the perspective of incongruity theory]. Chinese National Expo, 3, 112-115.

\section{Copyright Disclaimer}

Copyright for this article is retained by the author(s), with first publication rights granted to the journal.

This is an open-access article distributed under the terms and conditions of the Creative Commons Attribution license (http://creativecommons.org/licenses/by/3.0/). 